\title{
Mechanism of transfer film formation during repeat pass sliding of ceramic materials*
}

\author{
O. O. Ajayi and K. C. Ludema \\ Department of Mechanical Engineering, University of Michigan, Ann Arbor, MI 48109 \\ (U.S.A.)
}

(Received May 16, 1989; revised February 28, 1990; accepted April 10, 1990)

\begin{abstract}
The formation of transfer film and the consequent effects on the friction and wear behavior of ceramic materials during repeat sliding contact were studied. This was done using four structural ceramics, namely silicon nitride, silicon carbide, alumina and zirconia, with a cylinder-on-flat test configuration.

The transfer film consists of reattached fine wear debris particles, the film, whenever formed, is strongly attached, enough to resist being wiped off by the slider. Calculations suggest that the fine particles are attached primarily by van der Waals forces and to a lesser extent by clcctrostatic attractive forces. As a consequence, the formation of transfer film leads to a decrease in the wear rate because of the 'protecting' role of the film. The presence of the film at the contact interface also results in high friction. The presence of a liquid environment and/or surface active species reduces the particle adhesive forces and hence can inhibit the formation of a transfer film.
\end{abstract}

\section{Introduction}

Ceramic materials are good prospects for tribological applications, especially under severe conditions. This is because they have better corrosion and high temperature resistance than do the metallic materials. Consequently, the wear of ceramic materials has received much attention over the last decade.

Much of the attention so far in wear studies of ceramics has been on the surface damage and material removal processes. Wear mechanisms involving plastic deformation, brittle fracture and tribochemistry have been reported (see for example refs. 1-9). Attempts have also been made to connect the wear behavior of ceramics with their mechanical properties such as hardness, fracture toughness and elastic modulus (see for example refs. 10 and 11). In spite of the large amount of work done to date, an aspect of ceramic wear that has received little or no attention is the large transitions and variations that are seen in friction and wear rates during sustained sliding.

During repeat pass sliding, wear rates are often high at the beginning of a test and then decrease to a steady state at some later point. This is

*Paper presented at the International Conference on Wear of Materials, Denver, CO, U.S.A., April 8-14, 1989. 
due to a combination of several factors. The most commonly stated reason for the initial high wear rate, at least for the sphere or cylinder on flat, is the high contact pressure at the beginning of sliding. The contact pressure decreases with time as the nominal contact area between the wearing surfaces increases.

A more likely source of wear rate reduction with time is the reattachment of some of the wear debris to form the so-called 'transfer film'. Through this process, some of the materials that become detached from the surfaces by wear remain in the wearing system. Formation of transfer film (material transfer) during sliding contact of some metallic materials has been reported by several investigators (see for example refs. 12-14). Similarly, transfer film formation has been observed when polymeric materials slide on each other [15] or against metals [16]. A previous paper reported the observation of transfer film in some ceramic materials in sliding contact [17], where it was found to coincide with transitions in friction and wear behavior. These transitions coincide with changes in surface roughness and appearance. It was further observed that the wear rates of ceramic materials are sometimes higher when lubricated than in dry sliding. This phenomenon has been observed by others [8,9]. This paper gives results of another study of the details of the origin and factors that may influence transfer film formation.

\section{Experimental details}

\subsection{Materials}

Four commercially available engineering ceramic materials were used for this study. The materials are hot-pressed silicon nitride $\left(\mathrm{Si}_{3} \mathrm{~N}_{4}\right)(\mathrm{NC}-132$; Norton Company, Worcester, MA), hot-pressed silicon carbide (SiC) (NC203; Norton Company, Worcester, MA), sintered alumina $\left(\mathrm{Al}_{2} \mathrm{O}_{3}\right)$ (Champion Spark Plug, Detroit, MI) and sintered zirconia $\left(\mathrm{ZrO}_{2}\right)$ (Y-TZP; Allied Signal, Troy, MI). Some of the properties of the materials are shown in Table 1.

TABLE 1

Some properties of the experimental materials

\begin{tabular}{lllllll}
\hline Material & $\begin{array}{l}\text { Density } \\
\left(\mathrm{g} \mathrm{cm}^{\mathbf{2}}\right)\end{array}$ & $\begin{array}{l}\text { Elastic } \\
\text { modulus } \\
(\mathrm{GPa})\end{array}$ & $\begin{array}{l}\text { Hardness }^{\mathrm{b}} \\
(\mathrm{kg} \\
\left.\mathrm{mm}^{-2}\right)\end{array}$ & $\begin{array}{l}\text { Fracture }_{\text {toughness }}^{\mathrm{b}} \\
\left(\mathrm{MN} \mathrm{m}^{-3 / 2}\right)\end{array}$ & $\begin{array}{l}\text { Poisson's }^{\mathrm{c}} \\
\text { ratio }\end{array}$ & $\begin{array}{l}\text { Grain size }^{\mathrm{b}} \\
(\mu \mathrm{m})\end{array}$ \\
\hline $\mathrm{Si}_{3} \mathrm{~N}_{4}$ & 3.2 & 310 & 1900 & 5.2 & 0.27 & 0.5 wide/2.2 long \\
$\mathrm{SiC}$ & 3.3 & 435 & 2508 & 4.0 & 0.17 & 1.5 \\
$\mathrm{Al}_{2} \mathrm{O}_{3}$ & 3.25 & 400 & 1500 & 3.4 & 0.237 & 10.0 \\
$\mathrm{ZrO}_{2}$ & 6.03 & 210 & 1326 & 6.7 & 0.24 & ${ }_{\mathrm{t}-0.5, \mathrm{c}=4.0}$ \\
\hline
\end{tabular}

${ }^{*}$ t, tetragonal; c, cubic.

${ }^{a}$ Values supplied by various material manufacturers.

${ }^{b}$ Measured values.

${ }^{c}$ From Engineering Property Data on Selected Ceramics, Battelle Columbus Laboratories. 
In $\mathrm{Si}_{3} \mathrm{~N}_{4}$, each silicon atom is covalently bonded to four nitrogen atoms, forming a SiN${ }_{4}$ tetrahedron which is the building block for the $\mathrm{Si}_{3} \mathrm{~N}_{4}$ structure. As a result of the covalent bonding, densification is very difficult; thus dopants are often added to aid densification during processing. The $\mathrm{Si}_{3} \mathrm{~N}_{4}$ used for this study was doped with some $\mathrm{MgO}$. The microstructure consists of an elongated $\beta-\mathrm{Si}_{3} \mathrm{~N}_{4}$ grain and a continuous grain boundary phase.

$\mathrm{SiC}$ also consists of covalently bonded silicon and carbon atoms, forming a coordinating tetrahedron which again is the building block of the SiC structure. Like $\mathrm{Si}_{3} \mathrm{~N}_{4}$, a sintering aid is needed for densification during processing. The $\mathrm{SiC}$ used for this study was doped with aluminum and the microstructure consists of equiaxed $\mathrm{SiC}$ grains with some second-phase material around the multiple grain junctions.

Alumina is an ionically bonded material wherein $\mathrm{O}^{2-}$ ions form an h.c.p. structure with two thirds of the interstitial octahedral sites occupied by $\mathrm{Al}^{3+}$. Unlike covalently bonded $\mathrm{Si}_{3} \mathrm{~N}_{4}$ and $\mathrm{SiC}$, undoped $\mathrm{Al}_{2} \mathrm{O}_{3}$ powder can be hot pressed or sintered to produce a high density material. Sintered undoped $\mathrm{Al}_{2} \mathrm{O}_{3}$, however, always undergoes exaggerated growth of a small fraction of the grains. To reduce this abnormal grain growth, dopants are often added. MgO was added to the material used for the present study as dopant, and the microstructure consists of $\alpha-\mathrm{Al}_{2} \mathrm{O}_{3}$ with a secondary phase of spinel $\left(\mathrm{MgAl}_{2} \mathrm{O}_{4}\right)$ in addition to a glassy phase around the grain boundaries.

Zirconia is also an ionic material with $\mathrm{Zr}^{4+}$ and $\mathrm{O}^{2-}$ ions. It has three structural polymorphs: a monoclinic structure below $1000{ }^{\circ} \mathrm{C}$, a tetragonal between 1000 and $2300{ }^{\circ} \mathrm{C}$, and a cubic structure from $2300{ }^{\circ} \mathrm{C}$ up to its melting point. The transformation monoclinic $\rightarrow$ tetragonal is accompanied by a volume change (decrease) which could reduce the strength of the material because of the local tensile stresses imposed by the process. This constitutes a problem during an application under a moderate temperature, where the transformation can be activated. The present solution to this problem is to stabilize (at room temperature) either the cubic or the tetragonal phase through the addition of a dopant. The presence of the tetragonal phase is, however, more desirable, because the volume increase accompanying the tetragonal $\rightarrow$ monoclinic transformation imposes local compressive stresses and thereby increases the toughness of the material (transformation toughening). The zirconia used for the present study is tetragonal polycrystal doped with about $2.6 \mathrm{~mol} . \% \mathrm{Y}_{2} \mathrm{O}_{3}$ (Y-TZP). The microstructure consists of fine tetragonal grains and a small amount (about 5\%) of cubic grains.

\subsection{Tests}

A schematic diagram of the test configuration used is shown in Fig. 1. It consists of a stationary cylinder, $1.5 \mathrm{~mm}$ in radius and $3 \mathrm{~mm}$ long, sliding on a rotating flat surface. The flat specimens have a dimension of $20 \times 20 \times 5$ $\mathrm{mm}$. The stationary pin was attached to a cantilever loading arm. A strain gauge was mounted on the cantilever arm to measure the frictional force. The pin and flat specimens were ground with a series of abrasive SiC paper down to 600 grit. The surface roughnesses for the four materials are shown 


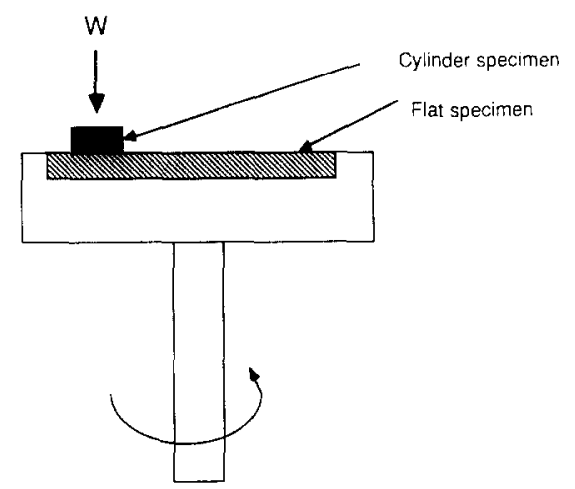

Fig. 1. Schematic diagram of the cylinder-on-flat test apparatus.

TABLE 2

Surface roughness $R_{\mathrm{a}}$ for the flat specimen in the four materials

\begin{tabular}{lllll}
\hline Material & $\mathrm{Si}_{3} \mathrm{~N}_{4}$ & $\mathrm{SiC}$ & $\mathrm{Al}_{2} \mathrm{O}_{3}$ & $\mathrm{ZrO}_{2}$ \\
$R_{\mathrm{a}}(\mu \mathrm{m})$ & 0.042 & 0.044 & 0.217 & 0.025 \\
\hline
\end{tabular}

in Table 2. Both the pin and the flat specimens were cleaned with distilled water and acetone.

All four materials were rubbed against each other in various combinations with the sliding direction perpendicular to the axis of the cylindrical pin. Loads of 13.7 and $25.5 \mathrm{~N}$ were used. All tests were done under room conditions $\left(23{ }^{\circ} \mathrm{C}\right.$; about $45 \%$ relative humidity) and at a constant sliding speed of $0.25 \mathrm{~m} \mathrm{~s}^{-1}$. The friction was continuously measured and recorded with a chart recorder during the entire test duration. The pin wear and flat wear were determined from the dimension of the wear scar. The scar dimension of the pin was determined using an optical microscope, while the scar dimension on the flat was determined by a surface tracer. Wear measurements were made after 10,100 and $250 \mathrm{~m}$ of sliding.

The worn surfaces were examined in a scanning electron microscope equipped with an energy-dispersive spectroscopy capability. The specimens were carbon coated to prevent charging during examination in the scanning electron microscope.

\section{Results}

\subsection{Friction and uear}

The frictional behavior of various sliding couples is shown in Fig. 2. In general, two kinds of behavior were observed: (1) a quick rise in friction to a peak value, followed by a decrease to a constant value and (2) a more gradual increase in the friction to a nearly constant value. A summary of 


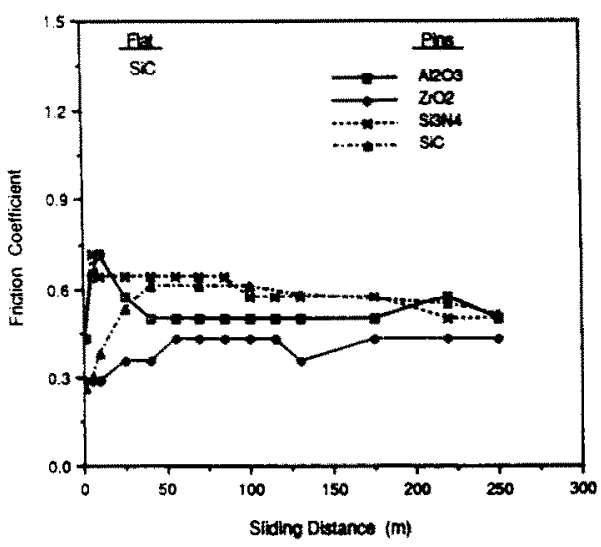

(a)

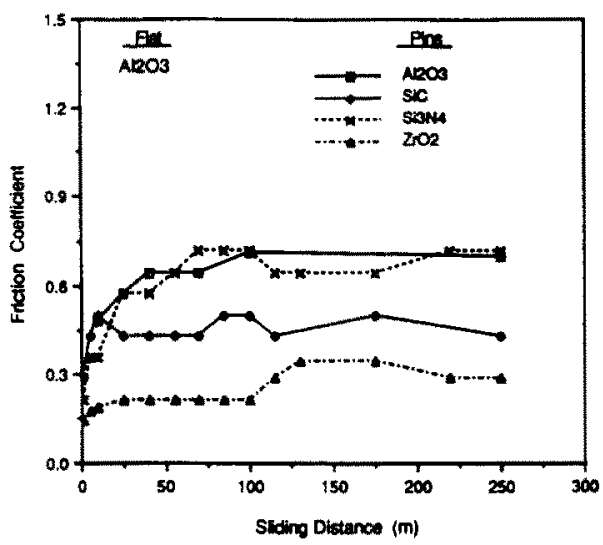

(c)

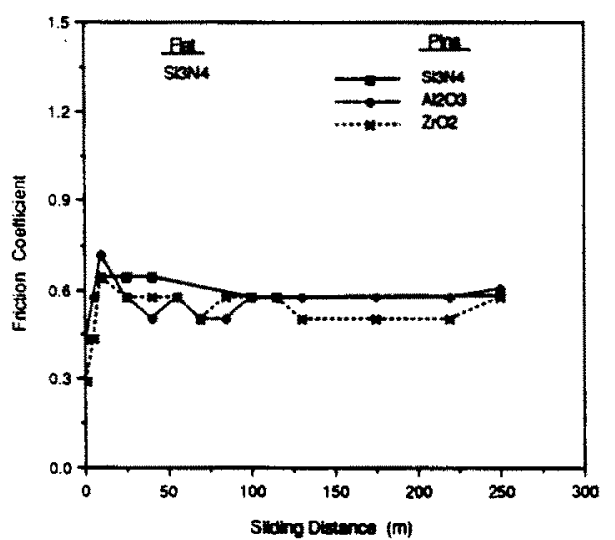

(b)

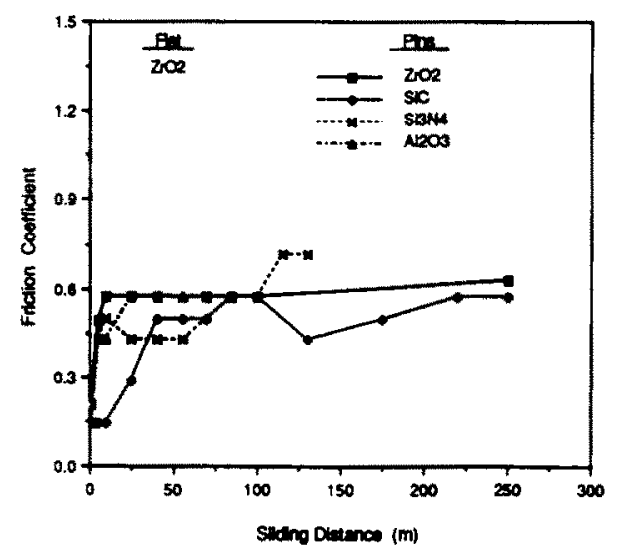

(d)

Fig. 2. Friction coefficient for various sliding couples at a load of $1.4 \mathrm{~kg}$ : (a) various pins on SiC flat; (b) various pins on $\mathrm{Si}_{3} \mathrm{~N}_{4}$ flat; (c) various pins on $\mathrm{Al}_{2} \mathrm{O}_{3}$ flat; (d) various pins on $\mathrm{ZrO}_{2}$ flat.

the behavior of various matcrial combinations is shown in Table 3 . On an $\mathrm{SiC}$ flat, both $\mathrm{Al}_{2} \mathrm{O}_{3}$ and $\mathrm{Si}_{3} \mathrm{~N}_{4}$ sliding pins showed a quick rise in friction to a peak value and then a decrease to a constant value, while $\mathrm{SiC}$ and $\mathrm{ZrO}_{2}$ showed a more gradual increase in friction at the early part of sliding to a nearly constant value (Fig. 2(a)). For the $\mathrm{Si}_{3} \mathrm{~N}_{4}$ flat, all the pins showed a very quick rise in friction for the first $10 \mathrm{~m}$ of sliding to a peak value and then a slight decrease to a constant value (Fig. 2(b)). On the $\mathrm{Al}_{2} \mathrm{O}_{3}$ flat, all pins except $\mathrm{SiC}$ showed a more gradual rise in the friction to a constant value (Fig. 2(c)). With a $\mathrm{ZrO}_{2}$ flat, for all pins, the friction showed a rapid rise in the early part of sliding to a constant value (Fig. 2(d)).

Wear in each of the different material pins as a function of the sliding distance after sliding on various material flats is shown in Fig. 3. The summary of the maximum amount of wear of the pins in various combinations is also 
TABLE 3

Summary of the friction and wear behavior of various sliding couples

\begin{tabular}{|c|c|c|c|c|}
\hline Flat & Pin & Friction & Pin wear & Flat wear \\
\hline $\mathrm{SiC}$ & $\begin{array}{l}\mathrm{SiC} \\
\mathrm{Si}_{3} \mathrm{~N}_{4} \\
\mathrm{Al}_{2} \mathrm{O}_{3} \\
\mathrm{ZrO}_{2}\end{array}$ & $\begin{array}{l}\text { II }(0.6) \\
\text { I }(0.6) \\
\text { I }(0.5) \\
\text { II }(0.4)\end{array}$ & $\begin{array}{l}\text { A }(0.035) \\
\text { B }(0.08) \\
\text { A }(0.01) \\
\text { C }(0.01)\end{array}$ & $\begin{array}{l}\mathrm{A}(0.22) \\
\mathrm{C}(0.25) \\
\mathrm{B}(0.11) \\
\mathrm{B}(0.01)\end{array}$ \\
\hline $\mathrm{Si}_{3} \mathrm{~N}_{4}$ & $\begin{array}{l}\mathrm{SiC} \\
\mathrm{Si}_{3} \mathrm{~N}_{4} \\
\mathrm{Al}_{2} \mathrm{O}_{3} \\
\mathrm{ZrO}_{2}\end{array}$ & $\begin{array}{l}\text { I }(0.6) \\
\text { I }(0.55) \\
\text { I }(0.5)\end{array}$ & $\begin{array}{l}\mathrm{B}(0.05) \\
\mathrm{C}(0.11) \\
\mathrm{B}(0.02)\end{array}$ & $\begin{array}{l}\mathrm{A}(0.2) \\
\mathrm{C}(1.3) \\
\mathrm{A}(0.1)\end{array}$ \\
\hline $\mathrm{Al}_{2} \mathrm{O}_{3}$ & $\begin{array}{l}\mathrm{SiC} \\
\mathrm{Si}_{3} \mathrm{~N}_{4} \\
\mathrm{Al}_{2} \mathrm{O}_{3} \\
\mathrm{ZrO}_{2}\end{array}$ & $\begin{array}{l}\text { I }(0.47) \\
\text { II }(0.65) \\
\text { II }(0.7) \\
\text { II }(0.3)\end{array}$ & $\begin{array}{l}\mathrm{C}(0.004) \\
\mathrm{A}(0.02) \\
\mathrm{B}(0.03) \\
\mathrm{B}(0.02)\end{array}$ & $\begin{array}{l}A(0.04) \\
A(0.09) \\
C(0.06) \\
C(0.03)\end{array}$ \\
\hline $\mathrm{ZrO}_{2}$ & $\begin{array}{l}\mathrm{SiC} \\
\mathrm{Si}_{3} \mathrm{~N}_{4} \\
\mathrm{Al}_{2} \mathrm{O}_{3} \\
\mathrm{ZrO}_{2}\end{array}$ & $\begin{array}{l}\text { II }(0.55) \\
\text { I }(0.5) \\
\text { I }(0.55) \\
\text { I }(0.55)\end{array}$ & $\begin{array}{l}\mathrm{B}(0.001) \\
\mathrm{A}(0.01) \\
\mathrm{A}(0.03) \\
\mathrm{A}(0.25)\end{array}$ & $\begin{array}{l}\text { B }(0.001) \\
\text { B }(0.001) \\
\text { B }(4.8) \\
\text { A }(3.0)\end{array}$ \\
\hline
\end{tabular}

\section{Friction}

I, quick rise to a peak value, followed by a decrease to a constant value.

II, gradual rise in friction to a constant value.

Number in parentheses is the constant friction coefficient value.

Wear

A, decreasing wear rate with sliding distance.

$\mathrm{B}$, constant wear rate with sliding distance.

$\mathrm{C}$, increasing wear rate with sliding distance.

Number in parentheses is the amount of wear at the end of the test $\left(\mathrm{mm}^{3}\right)$.

shown in Table 3. In general, the $\mathrm{SiC}$ pin showed the least wear of all the pins when sliding on various flats except for the $\mathrm{SiC}$ flat. The $\mathrm{ZrO}_{2}$ pin also showed a smaller amount of wear when sliding on other material flats as compared with sliding on a $\mathrm{ZrO}_{2}$ flat. Figure 4 shows the variation in the wear of the flat specimens with sliding distance after mbbing with various pins. Again the summary is given in Table 3. Some facts are worth noting. The wear in the flat is always higher than in the pin. In general, the $\mathrm{Al}_{2} \mathrm{O}_{3}$ flat showed a very small amount of wear with all the pins and in fact shows some negative wear at the early part of sliding in some cases (Fig. 4(c)). This is due to transfer of material from the pin. The $\mathrm{ZrO}_{2}$ flat showed most wear when rubbed with the $\mathrm{Al}_{2} \mathrm{O}_{3}$ and $\mathrm{ZrO}_{2}$ pins but least wear with $\mathrm{SiC}$ and $\mathrm{Si}_{3} \mathrm{~N}_{4}$ pins. For the other two materials, the results were mixed.

\subsection{Microscopy}

Microscopic examination of the worn surfaces of the pin and the flat specimens showed that material removal did occur in almost all cases. In some cases, however, areas were identified where reattachment of some of 


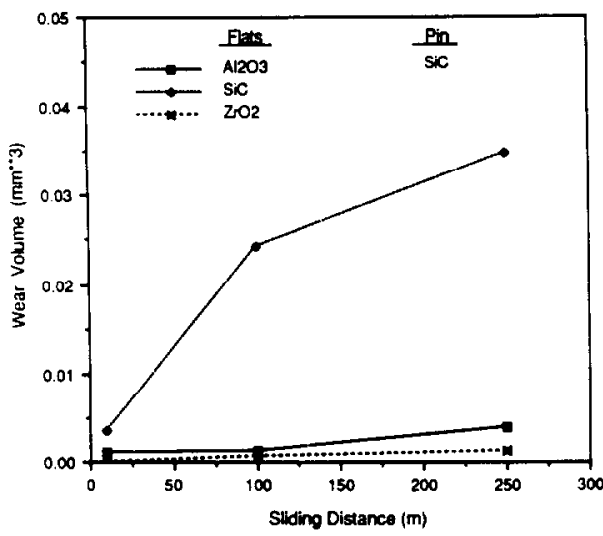

(a)

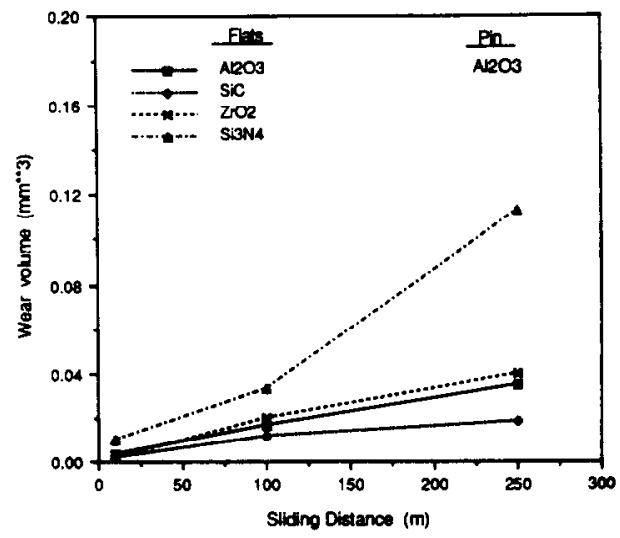

(c)

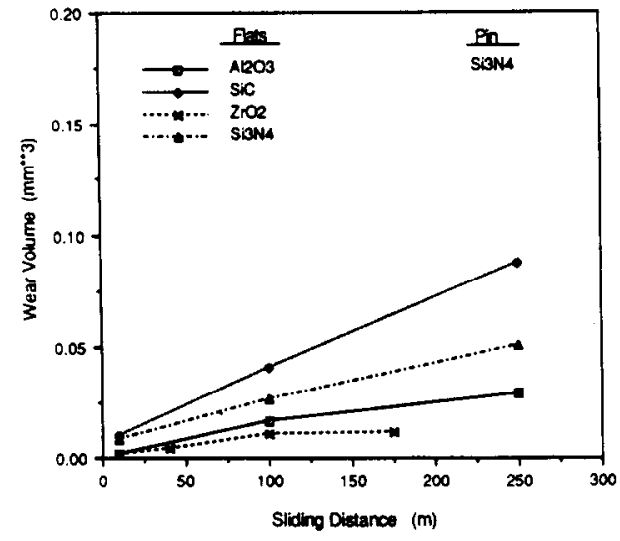

(b)

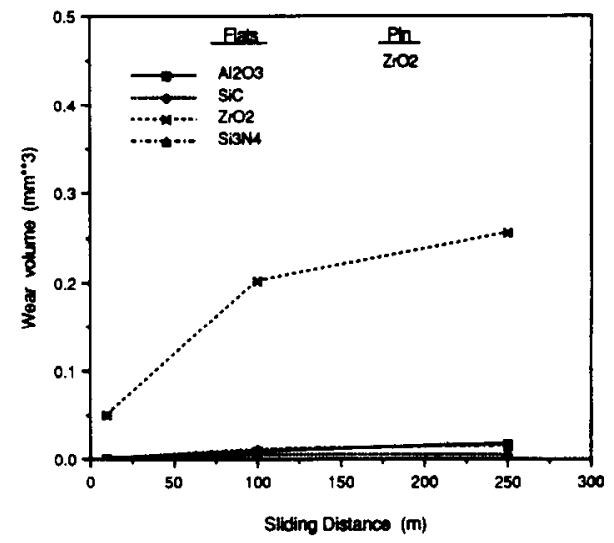

(d)

Fig. 3. Pin wear for each material after sliding on various flats at a load of $1.4 \mathrm{~kg}$ : (a) $\mathrm{SiC}$ pin wear; (b) $\mathrm{Si}_{3} \mathrm{~N}_{4}$ pin wear; (c) $\mathrm{Al}_{2} \mathrm{O}_{3}$ pin wear; (d) $\mathrm{ZrO}_{2}$ pin wear. It should be noted that the scale of the wear volume axes is different for each material.

the debris had occurred. Such regions were observed in both the pin and the flat specimens. This reattached debris region is termed the 'transfer film'. Figure 5 shows such a film formed after a pin of $\mathrm{ZrO}_{2}$ slid on an $\mathrm{Si}_{3} \mathrm{~N}_{4}$ flat. Although film formation was observed in several cases, the nature and the characteristics of the film are not always the same but depend on the sliding couples. In some cases a film was formed on only one component of the sliding couple; in other cases it formed on both. Furthermore, it was observed that the film is sometimes continuous and adherent (Fig. 6) and sometimes consists of 'islands' (Figs. 7 and 8). Sometimes the debris particles are deposited in surface pits produced by wear, without forming a continuous film (Fig. 9). A close examination of the film showed that it consists of very fine particles attached to the surface and to one another. Energy-dispersive 


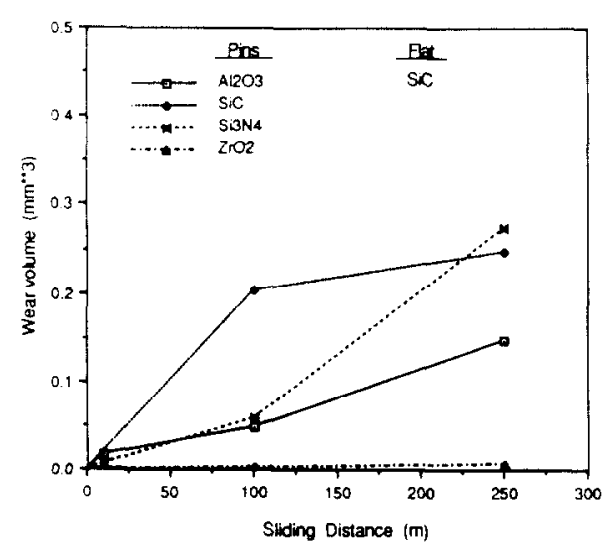

(a)

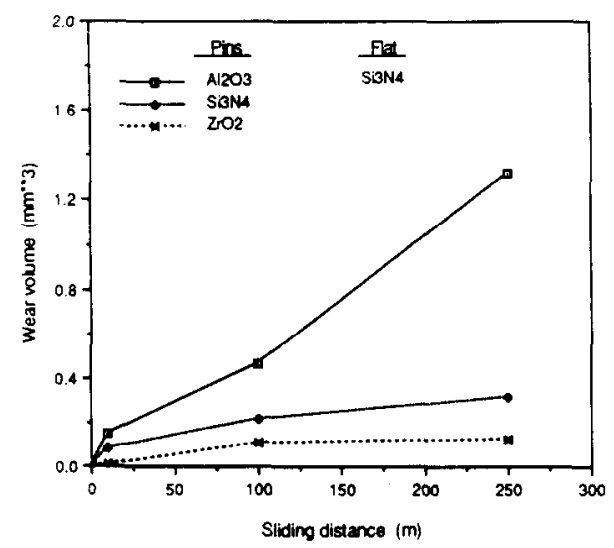

(c)

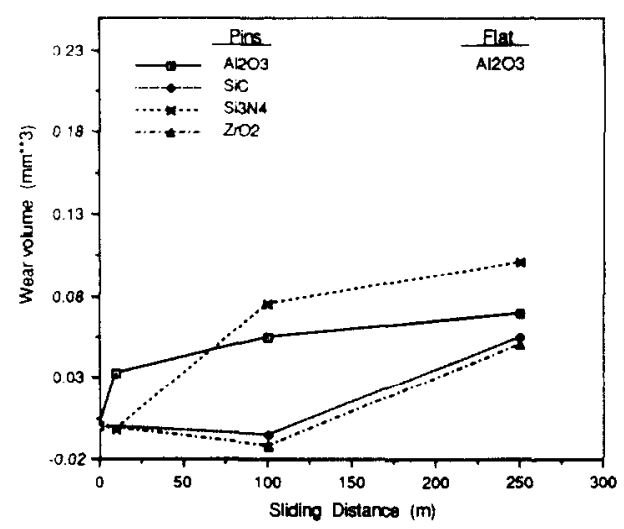

(b)

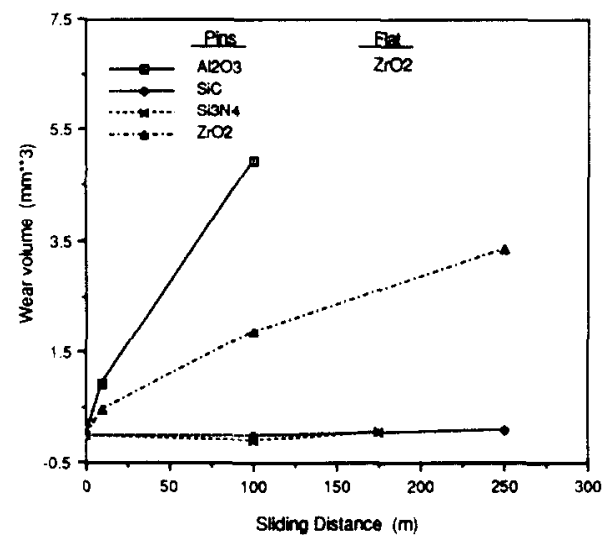

(d)

Fig. 4. Wear in different material flat specimens due to the sliding of various pins at a load of $1.4 \mathrm{~kg}$ : (a) $\mathrm{SiC}$ flat wear; (b) $\mathrm{Si}_{3} \mathrm{~N}_{4}$ flat wear; (c) $\mathrm{Al}_{2} \mathrm{O}_{3}$ flat wear; (d) $\mathrm{ZrO}_{2}$ flat wear. It should be noted that the scale of the wear volume axes is different for each material.

$\mathrm{X}$-ray analysis of the film showed that it consists of materials from the pin as well as from the flat (Figs. 6-8).

\section{Discussion}

When two ceramic surfaces are brought into sliding contact, wear debris is usually generated from both surfaces. Debris formation occurs by two processes in each of the four materials studied. One process involves fracture on the scale of the asperity size, which accounts for only a small amount of wear [18]. This process occurs in all the materials. The bulk of material removal, however, occurs on a larger scale, which varies from material to material. In $\mathrm{SiC}$, large-scale damage involves grain boundary failure, resulting 


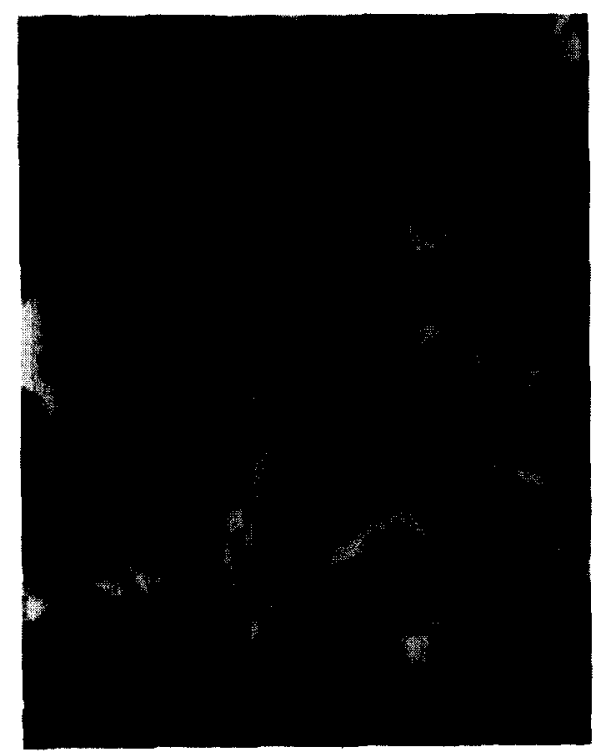

Fig. 5. Scanning electron micrograph of an $\mathrm{Si}_{3} \mathrm{~N}_{4}$ flat surface rubbed by a $\mathrm{ZrO}_{2}$ pin showing the transfer film.

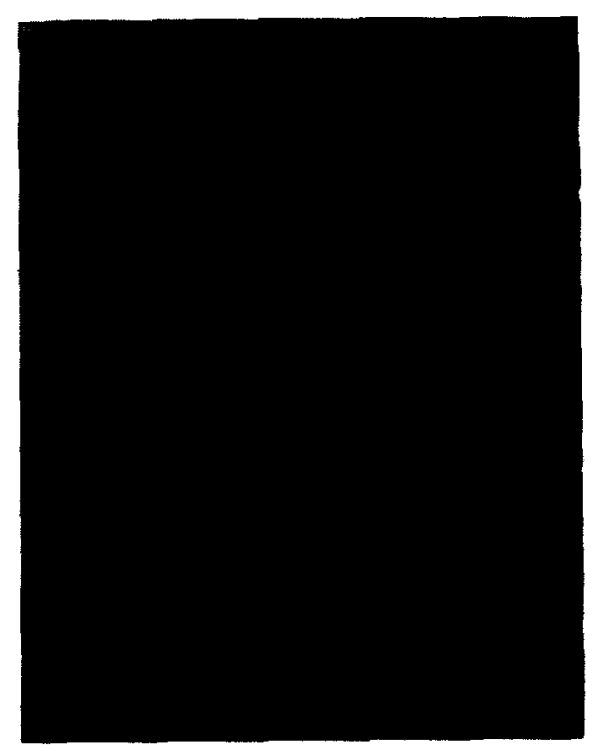

(a)

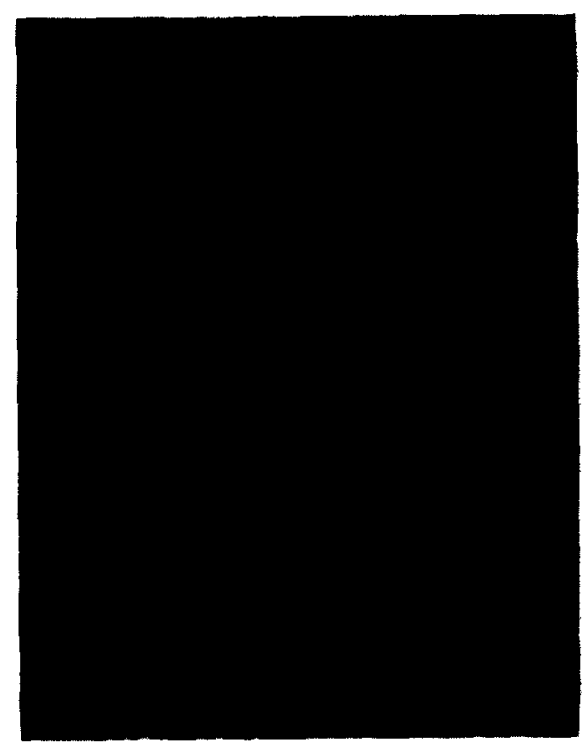

(b)

Fig. 6. (a) Scanning electron micrograph of an $\mathrm{Al}_{2} \mathrm{O}_{3}$ flat surface rubbed with a $\mathrm{ZrO}_{2}$ pin showing a continuous transfer film. (b) Energy-dispersive X-ray analysis map of zirconium showing that the film contains some $\mathrm{ZrO}_{2}$. 


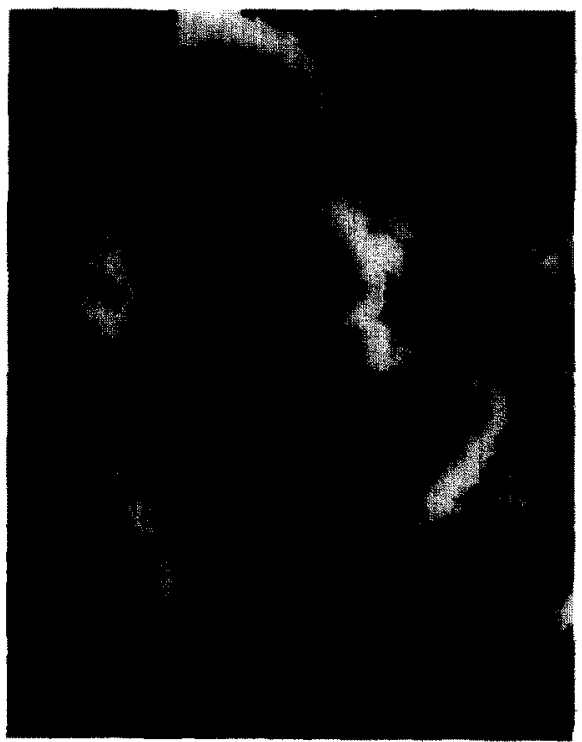

(a)

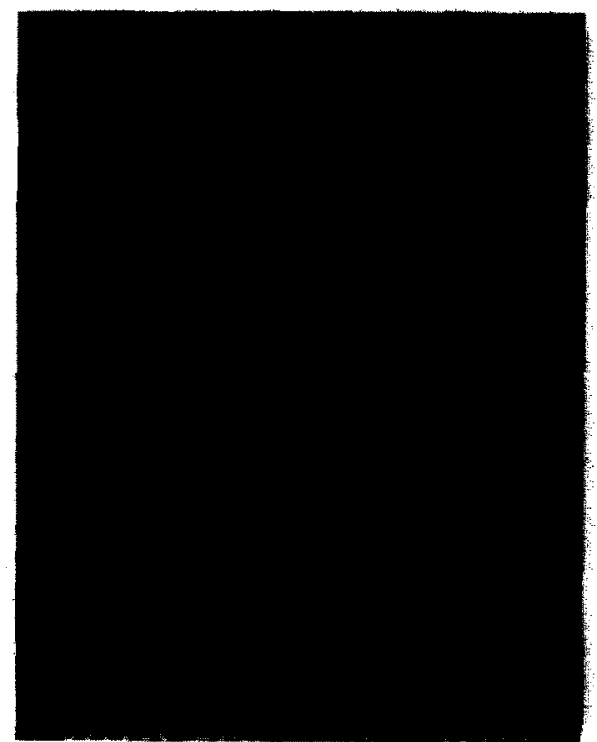

(b)

Fig. 7. (a) Scanning electron micrograph of an $\mathrm{Si}_{3} \mathrm{~N}_{4}$ flat worn by a $\mathrm{ZrO}_{2}$ pin showing the transfer film 'island'. (b) Energy-dispersive X-ray analysis map of zirconium indicating that the film contains some $\mathrm{ZrO}_{2}$.

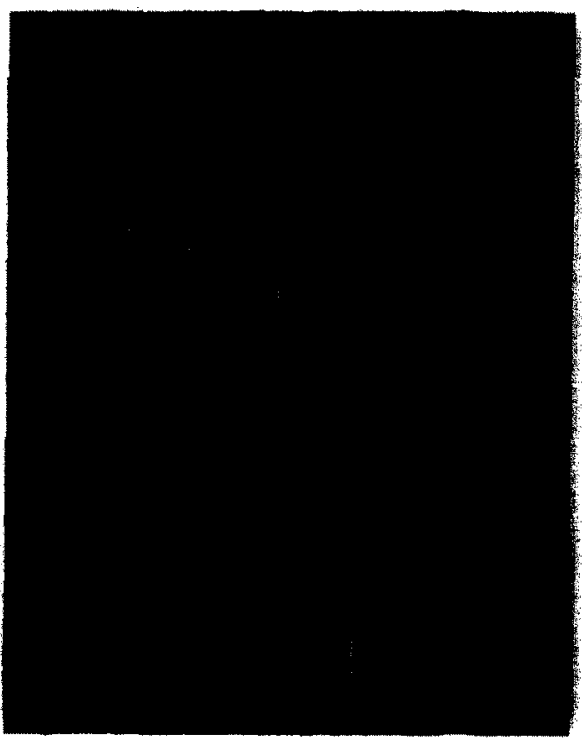

(a)

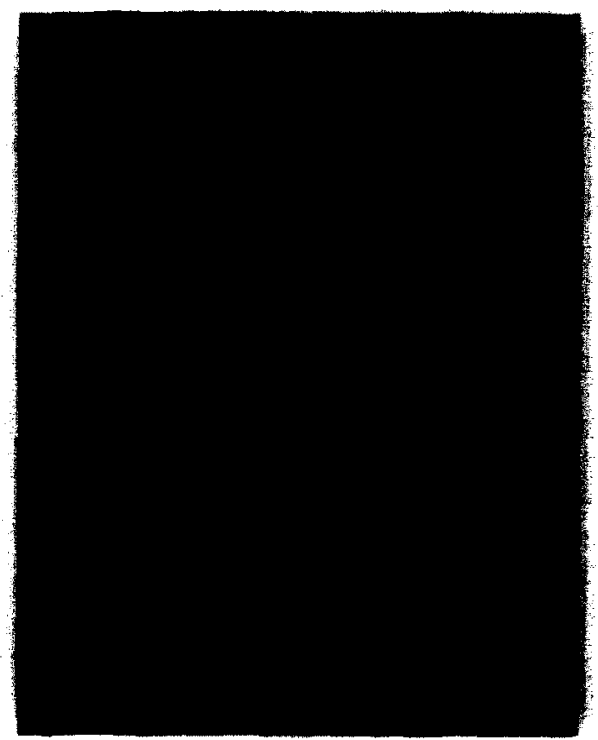

(b)

Fig. 8. (a) Scanning electron micrograph of an $\mathrm{Al}_{2} \mathrm{O}_{3}$ pln worn on an $\mathrm{SiC}$ flat showing transfer film formation. (b) Energy-dispersive $X$-ray analysis map of silicon indicating that the fllm contains some silicon from SiC. 

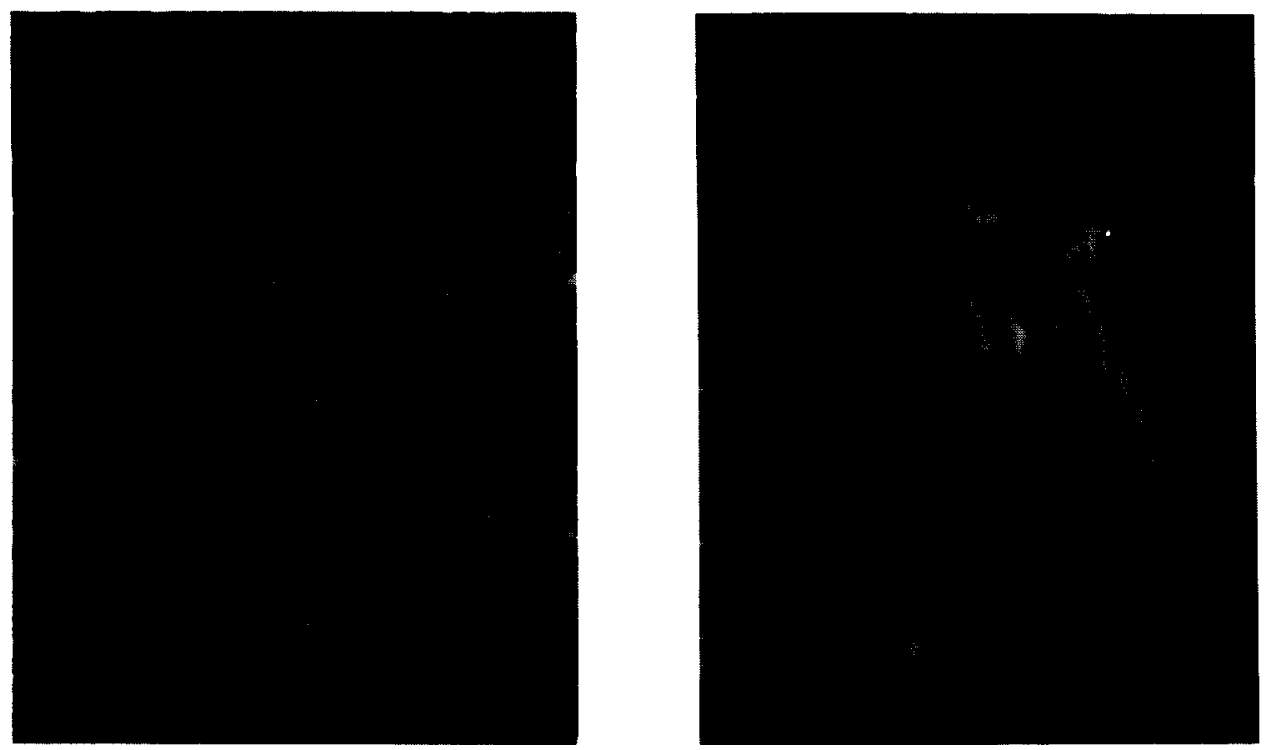

Fig. 9. Scanning electron micrograph of an $\mathrm{SiC}$ flat surface worn by a $\mathrm{Si}_{3} \mathrm{~N}_{4}$ pin showing the debris on the surface without forming a continuous film.

Fig. 10. Scanning electron micrograph of a $\mathrm{ZrO}_{2}$ pin surface worn on a $\mathrm{SiC}$ flat showing the grooves and scratches produced by trapped wear debris.

in the loosening of individual grains or several grains together. For $\mathrm{Si}_{3} \mathrm{~N}_{4}$, $\mathrm{Al}_{2} \mathrm{O}_{3}$ and $\mathrm{ZrO}_{2}$, material removal occurs by a progression of events beginning with plastic deformation and followed by crack initiation. Eventually flakeshaped particles separate from the surface as wear debris.

Some of the wear debris is lost from the system, but some is recycled at the contact interface (this may not occur in reciprocating sliding). The trapped debris particles produce further damage on both surfaces. Figure 10 shows the damage produced on a $\mathrm{ZrO}_{2}$ pin by trapped debris at the contact interface when the $\mathrm{ZrO}_{2}$ pin is rubbed on an $\mathrm{SiC}$ flat. The process of generation and trapping of wear debris is responsible for the quick rise of friction at the early stage of sliding that was observed for most of the couples. The low value of friction at the beginning of sliding is probably due in part to films of adsorbed species on the surface which may be displaced by sliding. The stated friction varies a little with cleaning method but a significant part of the friction rise is due to debris generation and trapping. The trapped debris undergoes fragmentation as sliding progresses, resulting in the formation of very fine debris particles. It is assumed that particle breakage occurs by brittle fracture without plastic deformation (this is a reasonable assumption for these ceramic materials since cleavage occurs more readily than does slip in ceramic crystals).

The final particle size can be estimated by energy balance before and after fracture. The particles cannot be broken into still finer particles when the particle size is such that its surface energy $U_{1}=2 \gamma A$ is larger than its 
strain energy to fracture given by $U_{2}=S^{2} V / 2 E$ [14], where $\gamma$ is the free surface energy, $2 A$ is the new surface area created after fracture, $S$ is the theoretical fracture strength, $V$ is the volume of a particle and $E$ is Young's modulus. For example in $\mathrm{Al}_{2} \mathrm{O}_{3}$, using $S \approx E / 10$ and $E / \gamma \approx 3 \times 10^{8}$, a particle with a diameter of the order of $10-50 \mathrm{~nm}$ is expected. Particle sizes of $5-50 \mathrm{~nm}$ have been observed experimentally [19]. We observed particles as small as $30 \mathrm{~nm}$ in the present study.

As a result of the large total surface area of the very fine particles, the total surface energy of a volume of particles is very high. There is a tendency in nature to minimize the total energy, and this is the driving force for particles to reattach to the surface and to each other (agglomeration). When two particles of surface energy $\gamma_{\mathrm{p}}$ are attached to each other over an area, the effective surface energy of such a system is given as $\gamma_{\mathrm{eff}}-2 \gamma-\gamma_{\mathrm{gb}}$, where $\gamma_{\mathrm{gb}}$ is the grain boundary energy. Thus a reduction in total surface energy is achieved by such particle attachment.

The mechanism by which the fine debris particles reattach to the surface and to each other is the same as for powder agglomeration (not to be confused with sintering). Two particles (or surfaces) may be held in contact by two major forces: van der Waals and electrostatic. These forces are essentially responsible for holding particles together in agglomerates [20-22] and we suggest, in transfer films. The forces have been observed to be strong enough to resist break-up of particle clusters by ultrasonic techniques [19] and to resist being wiped off by a slider as shown by the present study. A van der Waals force between two solids, which is always attractive, is due to the spontaneous electric and magnetic polarization of the molecules or atoms around the contact area. The electrostatic forces can be either attractive or repulsive depending on the net charge on the surface. The surface charges could be from the crystal structure (particularly in ionic crystals) when surfaces have a region of anion or a region of cation termination. The surface charges could also be from species that are adsorbed to the surface from the environment.

To estimate the approximate forces involved, one can use the van der Waals attractive forces between a spherical particle and a flat surface given as [23]

$F=\frac{C R}{6 z^{2}}\left(1+\frac{C}{6 \pi z^{3} H}\right)$

where $C$ is the Hamaker constant, $R$ is the particle radius, $H$ is the hardness and $z$ is the equilibrium separation between the particle and the flat. This separation is typically between 0.2 and $1 \mathrm{~nm}$, but a value of $0.4 \mathrm{~nm}$ is often used for force calculation [23-27]. As an example, for the $\mathrm{Al}_{2} \mathrm{O}_{3}$ couple, $C=2.2 \times 10^{-19} \mathrm{~J}$ [28], using $R=50 \mathrm{~nm}$ and $z=0.4 \mathrm{~nm}$, an attractive force of $8.14 \times 10^{-9} \mathrm{~N}$ is obtained. This force corresponds to an adhesive 'stress' of about $3.6 \mathrm{GPa}$.

Estimation of the electrostatic forces is more difficult owing to the problem of surface charge density. The adhesive stress resulting from elec- 
trostatic force for non-metallic materials is of the order of $30 \mathrm{MPa}$ [27], $1 \%$ of the van der Waals force. For the non-conducting materials used in these tests the electrostatic forces may be neglected.

The major force that tends to remove a transfer film from a surface is the frictional force. The frictional shear stress can be estimated from the nominal hertzian contact pressure $P_{\mathrm{n}}$ as $\mu P_{\mathrm{n}}$, where $\mu$ is the friction coefficient. Again, for $\mathrm{Al}_{2} \mathrm{O}_{3}$ this shear stress at a normal load of $13.7 \mathrm{~N}$ is about 20 MPa. This is smaller than the adhesive stress holding the particle to the surface and thus the film resists being wiped off by the slider. None the less, for a perfectly smooth pin and flat surfaces, a particle that adheres equally to the two surfaces will have a tendency to roll between the two surfaces during sliding contact. This rolling will be obstructed in rough surfaces. It then follows that the transfer film may form more readily on rougher surfaces. In the present study, the film was observed to form more on the flat specimens than on the pin specimens, and this may be in part due to the higher roughness of the flat specimen worn surfaces compared with those of the pins.

Although all the other factors that govern the direction and nature of the transfer film are not yet understood, it was observed that the characteristics of the film vary significantly, depending on the composition of the sliding couples. In general, for two ionic materials sliding together, a continuous and adherent film is formed, whereas for a couple of covalently bonded materials a continuous film does not form (often no film is formed). For an ionic and a covalent material couple, 'islands' are often formed (Fig. 11). The more continuous and adherent film of a couple of two ionic materials arises because the van der Waals forces are strong in such couples. This is because a major fraction of the surface layer consists of highly polarizable ions [29]. As a result the ionic materials have a large Hamaker constant with a typical value of $(20-50) \times 10^{-20} \mathrm{~J}$. On the contrary, for two covalently bonded materials sliding on each other, the van der Waals forces are relatively weak. The directionality of the bonds makes polarization more difficult, resulting in a low Hamaker constant with typical values of $(2-15) \times 10^{-20}$ J. For an ionic and a covalent material couple, the forces of adhesion is

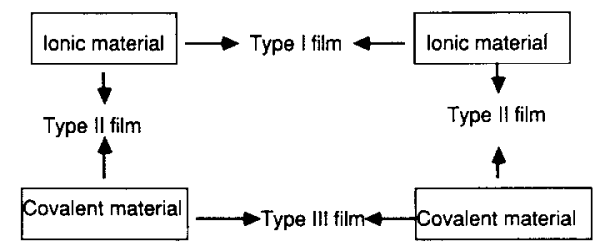

Type I :- Continous adherent film

Type II:- "Island" adherent film

Type III:- No distinct film; individual particle reattachment

Fig. 11. Different types of transfer film formed by ceramic materials sliding couples. 
determined by the 'composite' Hamaker constant given as $C_{12}=\left(C_{1} C_{2}\right)^{0.5}$. Factors and material properties other than bond type that may influence the transfer film formation are not yet fully understood. For instance, it is not known what governs the direction of a transfer between the sliding couples. In the four materials used for this study, $\mathrm{ZrO}_{2}$ was observed always to transfer onto $\mathrm{Al}_{2} \mathrm{O}_{3}$, but in the other couples there was often transfer in both directions. This is an area that requires further study.

The transfer film is still part of the wearing system and is formed from the wear debris originally generated. Thus the wear rate, which is the rate of material lost from the system, essentially is the rate of debris generation less the rate of debris reattachment through transfer film formation. Consequently, the measured wear rate could be defined as

wear rate $=$ material loosening rate - material reattachment rate

When no transfer film forms, the reattachment rate is zero and the wear rate will then be equal to the material loosening rate. The results from the present study showed that the wear rate in couples that form a stable and adherent film exhibit much less wear than couples that do not form a thick transfer film.

The presence of an aqueous environment and lubricant could inhibit the formation of transfer film. This is due to a combination of several factors. There is the screening effect of the van der Waals forces by the liquid environment. For $\mathrm{Al}_{2} \mathrm{O}_{3}$ adhering in water, the Hamaker constant is reduced to $4.17 \times 10^{-20} \mathrm{~J}$. According to eqn. (1), the van der Waals attractive force then becomes $2.1 \times 10^{-9} \mathrm{~N}$. This corresponds to about a $75 \%$ reduction in the attractive van der Waals force compared with a 'dry' contact. In addition, if the aqueous or liquid environment contains surface-active species, the driving force for particle adhesion will be reduced. The species adsorb onto the particle surface and thereby liberates adsorption energy, which must be subtracted from the free energy of the particles. Furthermore, if the liquid contains a dissociable dissolved species, preferential adsorption of an ion onto the particle surface could occur. If two particles carrying adsorbed ion layers of the same charge sign are brought near each other, repulsive forces keep the particles apart. All these will definitely reduce the adhesion and hence transfer film formation. This environmental effect is particularly important in the application of a liquid lubricant to ceramic sliding couples that readily form a transfer film. Although the lubricant could (and does) reduce friction in such a system, it may (and often does), however, result in more wear.

Finally, in view of the significant effect of transfer film formation on the tribological behavior of sliding ceramic couples, wear equations and models for ceramic materials must include terms that account for the transfer film. From the present study, it appears that such a factor will include the bonding character of the sliding couple, their chemical reactivity, and environment. Also, formation of transfer film is a fact to be considered in selecting ceramic components for tribological systems. Material couples that readily form a transfer film will be best suited to applications that require 
high friction but low wear, whereas such couples should be avoided in applications that require low friction.

\section{Conclusions}

The following conclusions can be drawn from the present study of sliding contact between ceramic materials.

(1) Some of the debris generated at the early part of sliding is trapped at the contact interface. This results in a quick rise in friction and much damage on the contacting surfaces. The trapped debris is later crushed into very fine particles.

(2) As a result of the high total surface energy of the very fine particles, reattachment of the particles to the surface and to one another occurs. This reattached layer is called a 'transfer film'. The forces for reattachment involve van der Waals attractive forces as well as electrostatic attractive forces.

(3) The reattachment of the particle is strong enough to resist being wiped off by a slider during sliding contact. As a result, the film protects the surface from further damage, thereby reducing the wear rate.

(4) The presence of liquids and surface-active agents can interfere with and prevent the formation of a transfer film during wear. This occurs through a reduction in the driving force for film formation, as well as a reduction in the forces holding the film onto the surface. There could also be some physical transport of the loose particles away from the interface. This is a particularly important consideration when formulating liquid lubricants for ceramic materials.

(5) In view of the significant effect of the formation of a transfer film on the tribological behavior of ceramic materials, a term describing its mechanism and mechanics has to be included in ceramic wear equations and model formulation. Transfer film formation and its cffects must also be taken into account when selecting ceramic materials for tribological applications.

\section{References}

1 B. J. Hockey, J. Am. Ceram. Soc., 54 (1971) 223-231.

2 I. A. Cutter and R. McPherson, J. Am. Ceram. Soc., 56 (1973) 266-269.

3 O. O. Adewoye and T. F. Page, Wear, 70 (1981) 37-51.

4 Y. Enomoto and K. Yanlanika, in K. C. Ludema (ed.), Proc. Int. Conf. on Wear of Materials, Reston, VA, 1983, American Society of Mechanical Engineers, New York, 1983, p. 174.

5 R. L. Aghan and R. McPherson, J. Am. Ceram. Soc., 56 (1973) 46-47.

6 N. Wallbridge, D. Dowson and E. W. Roberts, in K. C. Ludema (ed.), Proc. Int. Conf. on Wear of Materials, Reston, VA, 1983, American Society of Mechanical Engineers, New York, 1983, p. 202.

7 T. Sugita, K. Veda and Y. Kanemura, Wear, 97 (1984) 1.

8 T. E. Fischer and H. Tomizawa, Wear, 105 (1985) 29-45.

9 S. Jahanmir and T. E. Fischer, Society of Tribologists and Lubrication Engineers Trans., 31 (1988) 32-43.

10 A. G. Evans and D. B. Marshall, in D. A. Rigney (ed.), Fundamentals of Friction and Wear of Materials, American Society for Metals, Metals Park, OH, 1981, pp. 439-452. 
11 M. A. Moore and F. S. King, Wear, 60 (1980) 123-140.

12 M. Kerridge and J. K. Lancaster, Proc. R. Soc. London, Ser. A, 236 (1956) 250-264.

13 E. Rabinowicz and D. Tabor, Proc. R. Soc. London, Ser. A, 208 (1951) 455-475.

14 D. A. Rigney, L. H. Chen, M. A. S. Naylor and A. R. Rosenfield, Wear, 100 (1984) 195-219.

15 V. K. Jain and S. Bahadur, Proc. Int. Conf. on Wear of Materials, St. Louis, MO, 1977, American Society of Mechanical Engineers, New York, 1977, pp. 487-493.

16 S. H. Rhee and K. C. Ludema, Proc. Int. Conf. on Wear of Materials, St. Louis, MO, 1977, American Society of Mechanical Engineers, New York, 1977, pp. 482-486.

17 O. O. Ajayi, S. C. Kang and K. C. Ludema, in F. A. Smidt and P. J. Blau (eds.), Engineered Materials for Advanced Friction and Wear Applications, American Society for Metals, Metals Park, OH, 1988, pp. 13-22.

18 O. O. Ajayi, Ph.D. Thesis, University of Michigan, Ann Arbor, MI, 1989.

19 E. Breval, J. Breznak and N. H. Macmillan, J. Mater. Sci., 21 (1986) 931-935.

20 G. P. Demopoulos and G. Pouskouleli, J. Met., 40 (6) (1988) 46-50.

21 V. V. Yaminsky, E. A. Amelina and E. D. Shchukin, Colloids Surf., 6 (1983) 63-71.

22 C. Bernhardt, Adv. Colloid Interface Sci., 29 (1988) 79-139.

23 M. Van den Tempel, Adv. Colloid Interface Sci., 3 (1972) 137-159.

24 D. Tabor, J. Colloid Interface Sci., 58, (1977) 2-13.

25 J. N. Israelachvili and D. Tabor, Proc. R. Soc. London, Ser. A, 331 (1972) 19-38.

26 N. Kallay, Mater. Res. Bull., 15 (1990) 41-47.

27 H. Krupp, Adv. Colloid Interface Sci., 1 (1967) 111-239.

$28 \mathrm{~J}$. Visser, Adv. Collvid Inlerface Sci., 3 (1972) 331-363.

29 W. D. Kingery, H. K. Bowen and D. R. Uhlmann, Introduction to Ceramics, Wiley, New York, 1976, p. 205. 